\title{
Theoretical Approaches to the Study of the Economy of Religion
}

\author{
Zoya Shwed \\ Doctor of Philosophical Sciences, Associated Professor, \\ Taras Shevchenko National University of Kyiv \\ (Kyiv, Ukraine) \\ E-mail: shwedzoya@yahoo.com \\ https://orcid.org/0000-0002-5766-1980
}

The purpose of the paper is to identify and analyze the basic principles of the economy of religion. Consideration of the methodological features of the study of economics and religion should ensure the definition of the conditions for the application of an interdisciplinary approach, in the relationship between the economy and religion. This involves solving the following tasks: first, to reveal the content of the modern approaches, to understanding the relationship between religion and the economy, as a special area of public life, and secondly, to analyze the main features of the influence of religion on the economy, and the influence of the economy on religion. The theoretical basis of the study is based on several groups of sources, which highlight the problem of the relationship between religion and the economy. First, it is the legal documents in which the object of the legal regulation is religion and its institutional foundations. Secondly, these are theoretical works that cover the issues of the interdependence of economic and religious spheres. Thirdly, there are religious studies, which argue for the need to establish the discipline of religious studies, and separate from it the economy of religion as an independent branch of knowledge.

Originality: The author proves that in analyzing the relationship between religion (as an institution) and economics, it is necessary to take into account their common social nature. This circumstance leads to the conclusion that the activities of religious organizations are observed and controlled by the humanitarian policy of the State. In order to ensure the rights and freedoms of its citizens, the State resorts to legislative activity, which determines the content and features of 'State vs Religion' relations, including also the economic sphere. The results of this legislative activity are expressed in the relevant regulatory acts and laws.

Conclusions: The relationship between the economy and religion is found in the praxiological and institutional levels. The religious traditions of the world, in their doctrines, contain elements of Canon Law that regulate economic activity in the private and public areas. These elements determine the content and features of economic practices and form a special perception of the nature and function of the economy. The attention of the State to these factors, contribute to the expansion of the rights and freedoms of its citizens, which affects the results of sustainable economic development.

Keywords: humanitarian studies; economy of religion; religious activity; economic activity

Received: December 26, 2018; accepted: January 29, 2019

Future Human Image, Volume 11, 2019: 83-90.

https://doi.org/10.29202/fhi/11/9

(C) Shwed, Zoya, 2019 


\section{Introduction}

The processes of integration and differentiation, associated with globalization, today affect all spheres of public life. We are witnessing the emergence of new commercial markets where supply and demand are beginning to spread to private life, which until recently, remained in the competence of such public institutions as a Church or Religious Organization. This assertion may seem controversial, given the fact that the practice of economic activity of organized religion was always accompanied, throughout its existence, with the sale of indulgences, profits from the lease of property, etc. The present form of the presence of religion in the economic sphere are different; the novelty of the use of mechanisms of popularization, which are in essence, the activities of "marketing departments", are designed to promote the formation of demand and "the sale of spiritual happiness." The specificity of this analysis is also due to the fact that religion, being an element of culture (sometimes it is its essential core, method of preservation, or form of expression), begins to be understood as "industry of production", which is affected by the humanitarian policy of the State in the field of culture, religion, or between State's relations with the Church and Religious Organizations. ${ }^{1}$ For example, in Ukraine there is the State Committee of Ukraine for Nationalities and Religions, (Resolution of the Cabinet of Ministers of Ukraine "On Approval of the Regulation on the State Committee of Ukraine for Nationalities and Religions" No. 201, dated February 14, 2007), which is a structural subdivision of the Ministry of Culture of Ukraine.

As a specially authorized central executive body, the Committee is expected, within its competence, to contribute to the implementation of state policy in the field of religion, and relations with the Church and Religious Organizations. In this context, the question arises as to the content of the economic component of these relations, since they affect not only the issues of protecting the rights and freedoms of religious communities, and their cultural autonomy, etc., but they also address the problem of resolving disputed issues that may arise between religious organizations of different religions. In addition, the Committee prepares proposals for the formation and implementation of State Policy in the religious sphere, including the drafting the State Budget and the State Program of Economic and Social Development of Ukraine. The acquisition of such extensive authority by this body is due to the fact that the State understands the role of religion as a factor that affects the specifics of the functioning of modern society. At the same time, it seems appropriate to single out another aspect of the study of economics and religion. Its essence is conditioned by the fact that for the economic system, religion often appears as a focus (or even a legitimizing condition) of those values that are used by participants in economic relations.

\section{Characteristics of religious values in the economy of religion}

Religious values that appear during the process of meaningful saturation of the concept of "common good" are specifically represented in the system of socio-economic relations, like education, and mass media, and in the political and legal plane, like labor legislation and state security. As you know, public good can be interpreted as a benefit that is freely consumed by the whole society on a paid or non-paid basis, is a means to meet the needs on the individual or collectives level, and is a combination of goods or services, the distribution of which is provided by the activities of the State. Thus, there appears to be a certain contradiction.

\footnotetext{
${ }^{1}$ See details [Shwed, 2015].
} 
Religious values, (expressed in the "religious product", which is to satisfy religious needs), occupy an important place in the system of public goods guaranteed by the State and are governed by State Regulation. At the same time, if you use the terminology of economic theory, the process of developing and distributing religious products (in the form of services) can also be interpreted through the Laws of Market Economy, thus creating a specific Market Reality in the field of cultural production, designed to satisfy religious needs.

Based on the modern typologies of the concepts of Economy of Religion, their richness of content is determined by in the following characteristics — an absence of a commercial component in the religious values as a component of a cultural product, an orientation towards sustainable human development, raising the level of human well-being, expanding the horizons for creativity, and preserving peace and promoting non-violent forms of cooperation in all spheres of public life. As we see, for today's typologies of the economy of religion, the idea of a "progressivist" orientation in comprehending the essence of the expression of the economic aspect of religious practices, like those that lead to an improvement in the life of the individual. Become their starting point. In this case, cultural activity, implemented in a religious form, is conceived as a special representation of the spirituality of mankind expressed in the praxiological cut. In addition, it should be noted that the analysis of the financial aspect of the activities of subjects of religious practice, should take into account that such activities are carried out within the framework of the cultural policy of the State and its distribution of funds. In addition, this is directly related to the economic context of religious activity, as a kind of economic activity in general.

Religious activity can be understood as a certain segment of cultural activity, with the understanding that the latter is tangent to the moral aspects of human existence, and retains the elements of creativity, which are expressed in symbolic meanings. In his research, David Trosby formulates another requirement for the identification of cultural activities in terms of understanding the culture in the categories of economic theory. He concluded that there is a need to establish a certain form of "intellectual property" [Trosby, 2013: 20], which, according to the current legislation of Ukraine, gives a subject the right to profit from the results of intellectual or creative activity (Article 418 of the Civil Code of Ukraine). We believe this circumstance entails religious activity beyond exclusively cultural activities because, for religious activities, the right of intellectual property does not belong to its fundamental institutions. For world religions in general, it is outside the subject field of discussion, given the specificity of the interpretation of the notion of value. The uniqueness of the content of the religious meaning in religious practices is expressed in active messianic and missionary activities.

Although the process of commercialization in the field of religion is not sufficiently clear, we can aver, that this aspect of religious activity is still present, and the influence of religious factors on the formation of the peculiarities of economic systems in society and the systems of management, are in fact provided (M. Weber). At the same time, it should be noted that the ambiguity of the use of terms in the law might lead to social and political misunderstandings. It says, for example, in the UNESCO Convention on the Protection and Promotion of Forms of Cultural Self-expression (Clause 1, P.4), that "forms of cultural expressions, are those that result from the creative activity of individuals, groups, or communities, and have cultural content" [Convention, 2005]. It is clear that the form of expression of the person's creative activity may be the creation of a product (object), protected by copyright. At the same time, cultural content is saturated with symbolic meanings directly determined by the cultural identity of its creator, including his religious beliefs. 
Therefore, it seems legitimate to talk about the peculiarities of the spread of cultural (religious) services, referring this process to all varieties of cultural industries. In this context, the latter religious practices can be attributed to a variety of cultural_industries, which, after carrying out their activities as entities, satisfy the demand for religious services, the reason of which is the need for religious expressions of individuals or groups. In such circumstances, the consumer product forms the provision of both the needs of religious expression and the preservation of religious identity, which, when united, become the object of the cultural policy of the State. At this time, it is worth mentioning the provisions of the Law of Ukraine "On Culture", in which the definition of culture, makes it possible to consider the religion (culture) component. P.6., P.1. Article 1 of this law emphasizes that culture is the totality of material and spiritual heritage of a human community (ethnic group, nation), accumulated, fixed and enriched over a long period of time, and transmitted from generation to generation, including all kinds of arts, cultural heritage, cultural values, science, education, and it reflects the level of development of this community [Law of Ukraine, 2011]. Cultural goods are goods and services, produced in the process of carrying out cultural activities, in order to meet the cultural needs of citizens [Law of Ukraine, 2011]. As we see, this definition allows us to speak about the inclusion of religion in such spheres of public life, which until recently, were considered separate from religion. For example, in the Resolution of the Cabinet of Ministers of Ukraine "On State recognition of Higher Religious Education, Scientific Degrees and Academic Titles, issued by Higher Educational Institutions" of 19 August 2015 r. Number 652, approved the procedure for the recognition of this branch of knowledge as "Theology" [Resolution, 2015].

At the same time, in another Resolution of the Cabinet of Ministers of Ukraine "On Approval of the National Qualifications Framework" of November 23, 2011, No. 1341, knowledge is interpreted as scientific information, understood and retained by the subject, which is the basis of his conscious, deliberate activity [Resolution, 2011]. Knowledge is divided into empirical (factual) and theoretical (conceptual, methodological). However, the legislator leaves an unanswered question about what scientific information is and how it differs from the non-scientific one.

We believe, that the holding of an International Scientific and Theological Conference, "The Methodology of Theological Research: Problems and Prospects", should have brought attention to existing inconsistencies, as the need to resolve the contradictions that arise in connection with the incompatible - Scientific-Theological concept, and the awareness of the specifics of the methodological guidelines in the system of Theology. It should be noted that among the organizers of this event were the Resource and Research Center of the Euro-Asian Accreditation Association (Association of Protestant Evangelical Theological Educational Institutions), and other religious educational institutions, and among the non-religious attendees was the Center for Religious Studies of the National Pedagogical Drahomanov University. As we can see, contemporary discussions in interdisciplinary studies of humanitarian sciences, exacerbated the question of the interconnection of various spheres of social life, an important manifestation of which is, religious and economic activity.

\section{The relationship between religious and economic systems}

In the interpretations of the peculiarities of the relationship between religious and economic systems, particular attention is paid to determining the specifics of the influence of economic, financial and legal factors on the religious sphere. In our opinion, this approach is 
quite promising, given that the spread of established research practices in science opens the prospect of establishing new scientific fields. Being a scientific discipline, the economy of religion has incorporated into its methodological base, the main achievements of the theory and methods of economic science. In this regard, several analytical studies traditionally distinguish between several branches, depending on the methodological principles on which one or another scientific paradigm is based. If we proceed from the standpoint of theory, and methods of economic theory, then the economy of religion, as defined by Laurence Iannaccone, combines two types of analysis: microeconomics (the study of religious behavior), and econometrics (economic effects of religions, and their connection with phenomena such as extremism, political systems, and the level of happiness) [Iannaccone, 1998: 1466]. In this case, for disciplinary religious studies, the Economy of Religion becomes a science, studying the relationship between religion and economy: first, it is the influence of religious teaching on types of economic activity and normative religious and economic concepts, and secondly, the impact of the economy on the peculiarities of functioning religious complex.

It therefore seems impossible to attribute the economy of religion exclusively to religious studies, since it is aimed not only at the study of the peculiarities of the representation of "religious subjects in productive activities" and "the problem of the choice of rational means of using resources in order to expand the scope of providing spiritual services, maximizing their quality approximation to the needs of the believer". After all, if we exclude from this definition a religious component, then we go to the topics of micro- and macroeconomic theory, the concept-categorical apparatus of which includes the concept of production, consumption, human capital, competition, management, etc.

Proceeding from the structural and functional model of the analysis of social phenomena, proposed by Talcott Parsons, we can conclude that religion, being one of the aspects (manifestations) of human activity, is an element of culture, which is in constant transformation (through reproduction, change, and consumption). Therefore, religion, as a representative of culture, at the same time represents its functions, expressed in features of the content and ways of satisfying the spiritual needs of society, and of the individual. As we see, the specificity of these studies is manifested, particularly in the fact, that the main emphasis is placed on the interpretation of the relation of religious doctrine with the notions of practical activity expressed in labor, which is described as a special type of world attitude, because of the religious outlook (ideology). At the same time, we can observe that in the process of spreading practices of post-industrial society, labor began to be understood as a way of self-expression, and expression of creativity, which according to Sh. Roels acquired the character of nonmaterial production. Thus, it speaks of deepening the role of spiritually-practical activity, serving as a tool for meeting human needs, which is actively involved in religion, which is manifested, in particular, in the economic sphere. ${ }^{2}$ The latter is characterized by the presence of religion, due to the fact that, in the process of a religious organization becoming a legal entity, its inclusion in economic activity is ensured [See. for example: Borysova, 2014]. That is why it is advisable to talk about the emergence of a new field of research, the object of which is economic relations in the field of religious activity.

We agree with the need to study this issue separately, which more than likely belong to the subject of economic theory, and partly to jurisprudence because it focuses on the characteristics of "production, consumption, exchange and distribution." These characteristics are manifested at the level of behavioral practices of a particular person, organization or society as a whole.

${ }^{2}$ See [Parkhomenko, 2016; Chewning et.al., 1993]. 
However, this should also take into account the humanitarian component, which may be thought of as a basis for the formation of special types of production or consumption. Thus, we should not forget, that in the search for the meanings of self-expression, which is inherent in modern man, we should remember that it is affected by the constant challenges facing the person, in the modern, whirlwind pace, of cultural transformations.

Religion, as an integral part of the culture, saturates culture with "eternal moral values" [Convention, 2005], which, being rooted in the absolute, do not require additional legitimization, and are not optional but imperative. In this interpretation, the integrated link between religion and culture is manifested in the fact that, in specific types of practice, like production, social transformation, scientific and technical, etc., where culture is carried out, have an influence on the formation of economic consciousness. In addition, religion, by promoting a world perception and worldview, identified as religious, is conditioned and determined by the peculiarities of experience and practice. This specific experience depends on the features of the religious complex, in which the praxiological component is represented through the functioning of religious organizations, and all other subjects (priests, religious hierarchs, spiritual mentors, etc.). Considering the concept of "socio-cultural services", which can include the activities of clerics, we establish that their content and quality depend on the demand that arises in the community, and individuals, in the spiritual and intellectual areas. And this allows us to talk about the economic factors of the existence of religion. The Church, as one of the basic institutes of spiritual production (together with the institutions of science, education, culture and media), represents its influence on the transformations that take place in the politico-legal, and socio-economic spheres of public life.

A study by Robert Barro and Rachel McClair states that when studying factors of economic growth, should take into account the influence of religion, and identifying this factor as religiosity. In work Does Religion Affect Economic Growth and Happiness? [Campante \& Yanagizawa-Drott, 2015], the authors emphasize, that taking into account established empirically detectable variables (church attendance and religiosity), show that "economic growth is positively responsive to the degree of religious beliefs", especially in those societies where theistic concepts are widespread, and the religious branch is not regulated by the State, and where there is no compulsion to attend religious events. This statement makes us conclude that the observance of the principle of freedom of conscience, and a high level of religiousness, significantly increase the accuracy of the study in the religious segment, when studying the economic area of public life. Taking this opportunity, we would also like to share, in our opinion, this valuable conclusion, that was made as a result of this study. Economic growth, if linked to its analysis of the influence of religion, is observed in those communities where not only the beliefs in the afterlife are widespread, but the presence of its two dimensions, in which "the rod, represented by fear of hell, is more powerful for growth, than a carrot is from the perspectives of heaven" [Barro \& McCleary, 2001: 36].

On the other hand, it is clear that going to a church, builds the social capital, that determines the influence of religion on the adoption of a legal framework, that governs economic behavior, political and social changes, and then is also felt in the legal system, education, demographic changes and more. Similar results were obtained in the study of Philip Campanata and David Yanahizava-Drott, covered in the paper, "Does religion affect economic growth and the level of happiness? Evidence from Ramadan". By studying the economic implications of Islamic practices, economists have identified important facts that clarify the relationship between religion and economic growth. Since the level of production in Muslim countries is reduced 
during the observance of Ramadan, there is a growing sense of personal well-being, selfesteem, satisfaction influencing career choices and selection of human resources [Campante \& Yanagizawa-Drott, 2015]. Turning again to the question concerning the study of the economy of religion, it should be noted that open discussions about the economic activity of the church, as an organization, are extremely necessary. The aspects of its existence, being outside of public discussion, leave many important, but unanswered questions, such as: what is the role of financial and economic training of active religious leaders for the successful functioning of the religious community, what are the nature, essence, and features of non-productive activity in religious structures, what is the difference between the practice of providing religious services in other areas, etc.? Although we have only started to study the economy of religion, works in this area are already well known, in particular the creative achievements of Adam Smith ("An Inquiry into the Nature and Causes of the Wealth of Nations"), Max Weber ("The Protestant Ethic and the Spirit of Capitalism"), and other authors of theories and analysis of the effects of religion on economy. In doing so, we share the views expressed by Robert Aumann, (Nobel Prize in Economics 2005), that the ideas presented by these authors had been previously formed in religious sources, primarily in the books Tanah and Talmud. Such an interpretation, Aumann argues, is based on the theory that the Talmud's authors had some mathematical methods available to substantiate the results fixed in Mishnah. In this regard, he gives relevant examples that the concept of strategy, price control and competition, supply and demand, the theory of economic justification of value and pricing, social choice, the threat of dishonesty, risk prevention, and equitable distribution all occur, for example, in the treatises of Mishna Bava Batra (sheet 89A, 197A), Mcott (sheet 3A), Ktoobot (sheet 15A, 93A), Bawa Micaa (sheet 2A), Gittin (sheet 45 A), and also the works of Rashi, Maimonides, Shmuel Ben Meyer and others.

\section{Conclusions}

Summarizing the foregoing, we note that the practical feasibility of studying the economy of religion independently is affected by a number of factors, which in their totality and circumstances, allow us to analyze complex social phenomena. Religious institutions, authorities, and other parties involved in the political life of a country have a significant impact on the pace of social development, which is one of the criteria for assessing economic growth. In our view, the study of the economy of religion will further enable the rethinking of extremely complex social phenomena, the nature of which is formed and determined by a whole complex of social practices, based in the present. A separate task of the economy of religion may be to study the problem of risks arising from the background of socio-economic transformations, which can lead to the process of religious extremism, and cause a crisis in interreligious relations of multinational and multireligious communities.

\section{미] References}

Barro, Robert, and Rachel M. McCleary. Religion and Economic Growth. NBER Working Paper 9682. 2001.

Borysova, V. Religious organizations - a functional type of non-profit organizations. Law of Ukraine. 2, 2014.

Campante, Filipe, and David Yanagizawa-Drott. Does Religion Affect Economic Growth and Happiness? Evidence from Ramadan. Quarterly Journal of Economics. Vol. 130, 2015. 
Chewning, Richard, John W. Eby, and Shirley J. Roels. Business through the eyes of faith. Moscow: Center of Universal Values, 1993.

Convention on the Protection and Promotion of the Diversity of Cultural Expressions, URL: http://zakon2.rada.gov.ua/laws/show/952_008

Iannaccone, Laurence. Introduction to the Economics of Religion. Journal of Economic Literature. Vol. 36, 1998.

Law of Ukraine "On Culture" (with changes). Information of Verkhovna Rada of Ukraine, 2011, № 24. URL: http://zakon3.rada.gov.ua/laws/show/2778-17

Parkhomenko, I.I. Problems of defining the concept of the economy of culture: cultural value. The Herald of Taras Shevchenko National University of Kyiv (Philosophy. Political science). №1 (120), 2016.

Resolution of the Cabinet of Ministers of Ukraine "On approval of the National Qualifications Framework” (with changes) 23 November 2011. № 1341. URL: http://zakon3.rada. gov.ua/laws/show/1341-2011-\%D0\%BF/paran12\#n12

Resolution of the Cabinet of Ministers of Ukraine "On State recognition of Higher Religious Education, Scientific Degrees and Academic Titles, issued by Higher Educational Institutions” (with changes) 19 September 2015, № 652. — URL: http://zakon2.rada.gov. ua/laws/show/652-2015-\%D0\%BF

Shwed, Zoya. Types of scientific rationality in religious studies. Sophia. 1 (5), 2016.

Trosby, David. Economy and Culture. Moscow: Higher School of Economics, 2013.

UNESCO universal declaration on cultural diversity. URL: http://unesdoc.unesco.org/images/0012/001271/127162e.pdf 